\title{
Abatacept in rheumatoid arthritis: survival on drug, clinical outcomes, and their predictors-data from a large national quality register
}

Giovanni Cagnotto ${ }^{1,2^{*}}$ (D), Minna Willim', Jan-Åke Nilsson ${ }^{1}$, Michele Compagno ${ }^{2,3}$, Lennart T. H. Jacobsson ${ }^{4}$, Saedis Saevarsdottir ${ }^{5,6}$ and Carl Turesson ${ }^{1,7}$

\begin{abstract}
Background: There are limited data regarding efficacy of abatacept treatment for rheumatoid arthritis (RA) outside clinical trials. Quality registers have been useful for observational studies on tumor necrosis factor inhibition in clinical practice. The aim of this study was to investigate clinical efficacy and tolerability of abatacept in RA, using a national register.

Methods: RA patients that started abatacept between 2006 and 2017 and were included in the Swedish Rheumatology Quality register $(N=2716)$ were investigated. Survival on drug was estimated using Kaplan-Meier analysis. The European League Against Rheumatism (EULAR) good response and Health Assessment Questionnaire (HAQ) response (improvement of $\geq 0.3$ ) rates (LUNDEX corrected for drug survival) at 6 and at 12 months were assessed. Predictors of discontinuation were investigated by Cox regression analyses, and predictors of clinical response by logistic regression. Significance-based backward stepwise selection of variables was used for the final multivariate models.

Results: There was a significant difference in drug survival by previous biologic disease-modifying antirheumatic drug (bDMARD) exposure $(p<0.001$ ), with longer survival in bionaive patients. Men (hazard ratio (HR) $0.86,95 \%$ confidence interval (CI) 0.74-0.98) and methotrexate users (HR 0.85, 95\% Cl 0.76-0.95) were less likely to discontinue abatacept, whereas a high pain score predicted discontinuation (HR 1.14 per standard deviation, 95\% Cl 1.07-1.20). The absence of previous bDMARD exposure, male sex, and a low HAQ score were independently associated with LUNDEX-corrected EULAR good response. The absence of previous bDMARD exposure also predicted LUNDEXcorrected HAQ response.
\end{abstract}

Conclusions: In this population-based study of RA, bDMARD naive patients and male patients were more likely to remain on abatacept with a major clinical response.

Keywords: Rheumatoid arthritis, Abatacept, Survival on drug, Treatment outcome, Response predictors

\footnotetext{
* Correspondence: giovanni.cagnotto@med.lu.se

${ }^{1}$ Rheumatology, Department of Clinical Sciences, Lund University, Malmö, Sweden

${ }^{2}$ Department of Rheumatology, Skåne University Hospital, Lund, Sweden Full list of author information is available at the end of the article
}

(C) The Author(s). 2020 Open Access This article is distributed under the terms of the Creative Commons Attribution 4.0 International License (http://creativecommons.org/licenses/by/4.0/), which permits unrestricted use, distribution, and reproduction in any medium, provided you give appropriate credit to the original author(s) and the source, provide a link to the Creative Commons license, and indicate if changes were made. The Creative Commons Public Domain Dedication waiver (http://creativecommons.org/publicdomain/zero/1.0/) applies to the data made available in this article, unless otherwise stated. 


\section{Background}

Rheumatoid arthritis (RA) is a chronic autoimmune disease that may lead to progressive joint damage and disability. In the last decade, outcomes of RA have improved considerably due to the recognition of the benefits of an early and aggressive treatment with disease-modifying antirheumatic drugs (DMARDs), with a structured follow-up, and to the development of biologic DMARD (bDMARDs). Disease remission or at least reduction in joint inflammation, prevention of joint damage, and preservation of function is now possible [1-4].

The rheumatology community, industry, and regulators have recognized the need for observational studies to monitor the safety of biologic therapy. Academia-initiated biologic registers are key not only for pharmacovigilance, but also to examine long-term effectiveness. Efficacy results observed in placebo-controlled randomized trial are sometimes different from the real-world effectiveness data. This can be due to patient selection, adherence to therapy, or other factors (i.e., Hawthorne effect) $[5,6]$.

Abatacept is a bDMARD acting through a selective inhibition of $\mathrm{T}$ cell co-stimulation. It was approved for RA treatment in Europe in 2007 (but available in Sweden for use in some patients already in 2006). Initially, it was listed in recommendations as an option only in patients with inadequate response to tumor necrosis factor (TNF) inhibitors [7], but it has subsequently been recommended as one of the first line bDMARDs for RA [8].

The Swedish Rheumatology Quality (SRQ) register has been used to study the effectiveness of TNF inhibitor switch in RA patient on a national level in Sweden [9]. It has also been included in previous international collaborations between European registers for studies of treatment with rituximab [10] and abatacept [11] for RA. Data on patients treated with abatacept (characteristics, diagnosis, previous treatment, and outcomes) have been collected in the SRQ register since abatacept was first available in 2006.

There is limited data on abatacept efficacy and on predictors of clinical response in real-world as derived from a single national register. Most studies are based on pooled data from several registers [12] or multicenter studies from several countries [13]. Such studies may be affected by patient heterogeneity and differences in access to bDMARDs [12].

The aim of this study was to describe survival on drug and clinical effectiveness in RA patients treated with abatacept and to investigate predictors of remaining on treatment and having a significant clinical response, in a national cohort.

\section{Patients and methods}

\section{Study design}

This was an observational study, based on a nationwide clinical RA register [14]. Clinical effectiveness was assessed as proportions of patients remaining on abatacept over time (drug survival) and as the proportions of patients remaining on therapy and achieving predefined standard clinical outcomes-according to the LUNDEX method [15], which has been used in several register-based studies of bDMARD effectiveness [16, 17].

\section{Source population}

The Swedish Rheumatology Quality register (SRQ) is a nationwide clinical register in Sweden of patients with chronic inflammatory joint diseases, including RA. RA patients starting bDMARDs have been included in the SRQ since 1999. The coverage of SRQ has been estimated at $87 \%$ of bDMARD treated patients, with no indications of compromised external generalizability regarding demography [18].

The SRQ covers clinical information on disease characteristics and antirheumatic treatment, prospectively recorded at treatment initiation and at subsequent visits. Dates of starting and stopping treatment, and the cause of discontinuing treatment are recorded by the physician who manages the patient at each visit, as part of regular clinical care. Studies on bDMARDs in the SRQ are coordinated by the Anti-Rheumatic Therapy in Sweden (ARTIS) Study group.

Patients with diagnosis of RA registered in the SRQ and starting abatacept treatment between April 2006 and November 2017 were included in the study. Clinical data from the SRQ were collected through data capture for the period 1 April 2006 to 30 November 2017.

\section{Survival on drug}

Survival on drug was estimated as the time to registered discontinuation of abatacept. Median time to discontinuation and estimated proportions still treated with abatacept at 6 and 12 months after treatment initiation were derived. Patients lost to follow-up (died, migrated from Sweden, or excluded from the SRQ for other reasons) or still treated with abatacept at the time of data capture were right censored. Reasons for abatacept discontinuation were also collected.

\section{Clinical response}

Clinical effectiveness of abatacept was evaluated by means of the European League Against Rheumatism (EULAR) response $[19,20]$ and by Health Assessment Questionnaire (HAQ) disability index (HAQ-DI) response [21], defined as improvement in HAQ score $\geq 0.3$ [22]. Baseline was defined as time of abatacept treatment start. In addition, proportions achieving disease activity score in 28 joints (DAS28) defined remission (DAS28 $<2.6$ ) or low disease activity (DAS28 $\leq 3.2$ ) [20] were calculated. Efficacy outcomes were evaluated at 6 months (i.e., the visit closest to 180 days, and within 150 to 240 days, after baseline visit) 
and at 12 months (i.e., the visit closest to 365 days, and within 300 to 450 days, after baseline visit). Moreover, patients achieving LUNDEX-corrected clinical outcomes were defined as those remaining on the drug and achieving the outcome [15]. Patients who discontinued abatacept treatment before the follow-up time points 6 and 12 months were considered non-responders for the corresponding LUNDEX-corrected outcome measures. In addition, LUNDEX-corrected proportions of clinical responders were also calculated as the fraction of patients remaining on treatment (including those with missing clinical data) multiplied by the proportion achieving the outcome among those with data available [15].

\section{Exposures}

Candidate predictors of drug survival and clinical effectiveness registered at baseline were age, sex, patient-reported pain on a visual analog scale (VAS), DAS28 and DAS28CRP, HAQ-DI, disease duration, route of abatacept administration, concomitant treatment with conventional synthetic DMARDs (csDMARDs), with methotrexate (MTX), with glucocorticoids, and previous bDMARD exposure. Three categories of patients were defined based on information collected in the SRQ prior to abatacept initiation: bionaive patients and those with 1 previous bDMARD or $\geq$ 2 previous bDMARDs.

\section{Statistics}

Survival on drug up to 5 years, by previous exposure to bDMARDs, was estimated using the Kaplan-Meier method (log-rank test). Predictors for drug discontinuation were investigated in Cox proportional hazards analyses, and for LUNDEX-corrected EULAR and HAQ responses in logistic regression models. In analyses of the relation between previous bDMARD exposure and outcomes, those who had been treated with $\geq 2$ bDMARDs (the largest category) were used as the reference. Variables with a $p$ value $<0.20$ in these analyses were retained for the starting multivariate model. Previous exposure to bDMARD treatment was forced in the model as an exposure variable. Significance-based backward stepwise selection of variables was used for the final multivariate model. In sensitivity analyses, all covariates with a $p$ value of $<0.10$ in the univariate models were included in the multivariate models. Furthermore, we also performed analyses including all covariates. Models were constructed with and without exclusion of covariates due to collinearity ( $r>0.3$, Pearson's test or Spearman's test, as appropriate).

\section{Results}

\section{Patient characteristics}

A total of 2716 patients with RA starting abatacept during the study period were included. Seventeen percent were bionaïve, $27 \%$ had been exposed to 1 previous
bDMARD, and $56 \%$ to $\geq 2$ previous bDMARDs. About half of the patients had intravenous administration of abatacept when first starting treatment. The mean disease duration at treatment start was 14.2 years. Most patients had active disease, with mean values for DAS28-CRP and HAQ-DI of 4.66 and 1.25, respectively. Variables reflecting disease activity and disease severity were comparable between the three categories of bDMARD exposure (Table 1). However, there were some differences in sex $(p<0.001)$, disease duration $(p<0.001)$, route of abatacept administration $(p<0.002)$, and glucocorticoids treatment $(p<0.001)$. Seventy-two per cent of patients in the bDMARD naïve group were women, while about $80 \%$ were women in the bDMARDs experienced groups. Bionaïve patients had a shorter disease duration (mean 9.5 years) in comparison with patients exposed to 1 previous bDMARD (mean 14.4 years) and to $\geq 2$ previous bDMARDs (mean 15.5 years). Forty-three percent of bionaïve patients were treated with intravenous abatacept compared with 52\% of the bDMARD experienced patients. Less bionaïve patients were treated with glucocorticoids (39\%) in comparison with bDMARD experienced patients $(47 \%$ and $52 \%$ in the 2 groups, respectively). The complete baseline characteristics of the cohort are shown in Table 1.

\section{Survival on drug}

Overall, $75 \%$ of the patients remained on treatment with abatacept at 6 months, and 55\% at 12 months. The corresponding proportions were $85 \%$ and $64 \%$ for bionaïve patients, $74 \%$ and $54 \%$ for those with 1 previous bDMARD exposure, and $73 \%$ and $52 \%$ for those exposed to $\geq 2$ previous bDMARDs. Overall, $50.0 \%$ of discontinuations were due to insufficient drug effect, $18.1 \%$ to side effects, $2.5 \%$ to persistent disease remission, and $29.4 \%$ to other reasons (non-specified reason, patient preference, pregnancy, death, etc). Median survival on abatacept was 1.74 years (95\% confidence interval (CI) 1.58-1.90), 2.23 years for bionaive patients (95\% CI 1.69-2.76), 1.68 years for those exposed to 1 previous bDMARD (95\% CI 1.34-2.01), and 1.56 years for those exposed to $\geq 2$ previous bDMARDs (95\% CI 1.35-1.76). There was a statistically significant difference in survival on drug between bionaïve and bDMARD experienced patients ( $p=0.001$, Fig. 1 ).

Bionaïve patients were less likely to discontinue treatment over time compared to those who had been treated with $\geq 2$ bDMARDs, whereas there was no difference between the subsets of bDMARD experienced patients (Table 2). In univariate analyses, male sex, lack of previous exposure to bDMARDs, and baseline treatment with methotrexate predicted longer survival on abatacept (Table 2). Moreover, higher DAS28-CRP, higher VAS pain, and higher HAQ score at baseline-predicted abatacept discontinuation (Table 2). In the multivariate model with significance-based backward stepwise selection of 
Table 1 Clinical characteristics at baseline visit by number of previous bDMARDs

\begin{tabular}{|c|c|c|c|c|}
\hline & Total & Bionaïve & 1 previous bDMARD & $\geq 2$ previous bDMARDs \\
\hline Number of patients (\%) & 2716 & $453(16.7)$ & $741(27.3)$ & $1522(56)$ \\
\hline Female sex (\%) & $2176(80.1)$ & $325(71.7)$ & $599(80.8)$ & $1252(82.3)$ \\
\hline Age at treatment start (years); mean (SD) & $59.3(13.3)$ & $61.7(14.0)$ & $60.7(12.9)$ & $57.8(13.0)$ \\
\hline Duration of RA at treatment start (years); mean (SD) & $14.2(11.4)$ & $9.5(11.1)$ & $14.4(11.8)$ & $15.5(10.8)$ \\
\hline Intravenous treatment & $1365(50.3 \%)$ & $194(42.8 \%)$ & $381(51.8 \%)$ & $790(52.1 \%)$ \\
\hline Subcutaneous treatment & $1338(49.3 \%)$ & $257(57.0 \%)$ & $355(48.2 \%)$ & $726(47.9 \%)$ \\
\hline ESR (mm 1st h); median (IQR) & $23(11-42)$ & $23(12-42)$ & $23.5(12-40.25)$ & $22(10-41)$ \\
\hline CRP (mg/l); median (IQR) & $9(3.5-23)$ & $11(5-24)$ & $8(3.48-23)$ & $8(3-22)$ \\
\hline DAS28; mean (SD) & $4.98(1.29)$ & $5.01(1.23)$ & $4.93(1.28)$ & $4.99(1.31)$ \\
\hline DAS28-CRP; mean (SD) & $4.66(1.13)$ & $4.64(1.14)$ & $4.57(1.13)$ & $4.70(1.13)$ \\
\hline VAS pain (0-100); mean (SD) & $60(23)$ & $58(24)$ & $59(23)$ & $62(22)$ \\
\hline VAS global (0-100); mean (SD) & $60(22)$ & $56(23)$ & $60(23)$ & $62(22)$ \\
\hline Swollen joint count (0-28); median (IQR) & $5(2-9)$ & $6(3-10)$ & $5(2-8)$ & $5(2-9)$ \\
\hline Tender joint count (0-28); median (IQR) & $6(3-10)$ & $6(2-11)$ & $6(3-10)$ & $6(3-11)$ \\
\hline HAQ-DI (0-3); mean (SD) & $1.32(0.63)$ & $1.16(0.63)$ & $1.30(0.65)$ & $1.37(0.62)$ \\
\hline Physicians global (0-4); median (IQR) & $2(2-3)$ & $2(2-3)$ & $2(2-3)$ & $2(2-3)$ \\
\hline Current methotrexate & $1288(57 \%)$ & $196(55 \%)$ & $373(61 \%)$ & 719 (55\%) \\
\hline Current glucocorticoids & $1316(49 \%)$ & 176 (39\%) & $345(47 \%)$ & 795 (52\%) \\
\hline Glucocorticoids dose in mg, prednisolone equivalent; mean (SD) & $7.5(4.2)$ & $7.6(3.9)$ & $6.9(4.0)$ & $7.8(4.3)$ \\
\hline Current csDMARD & $1489(55 \%)$ & $237(52 \%)$ & 425 (57\%) & $827(54 \%)$ \\
\hline
\end{tabular}

Missing data: Duration of RA at treatment start (years), 17; intravenous/subcutaneous treatment, 13; ESR, 714; CRP, 580; DAS 28, 921; CRP, 811; VAS pain, 748; VAS global, 711; swollen joint count, 624; tender joint count, 625; HAQ-DI, 825; physician global, 711; current methotrexate, 439

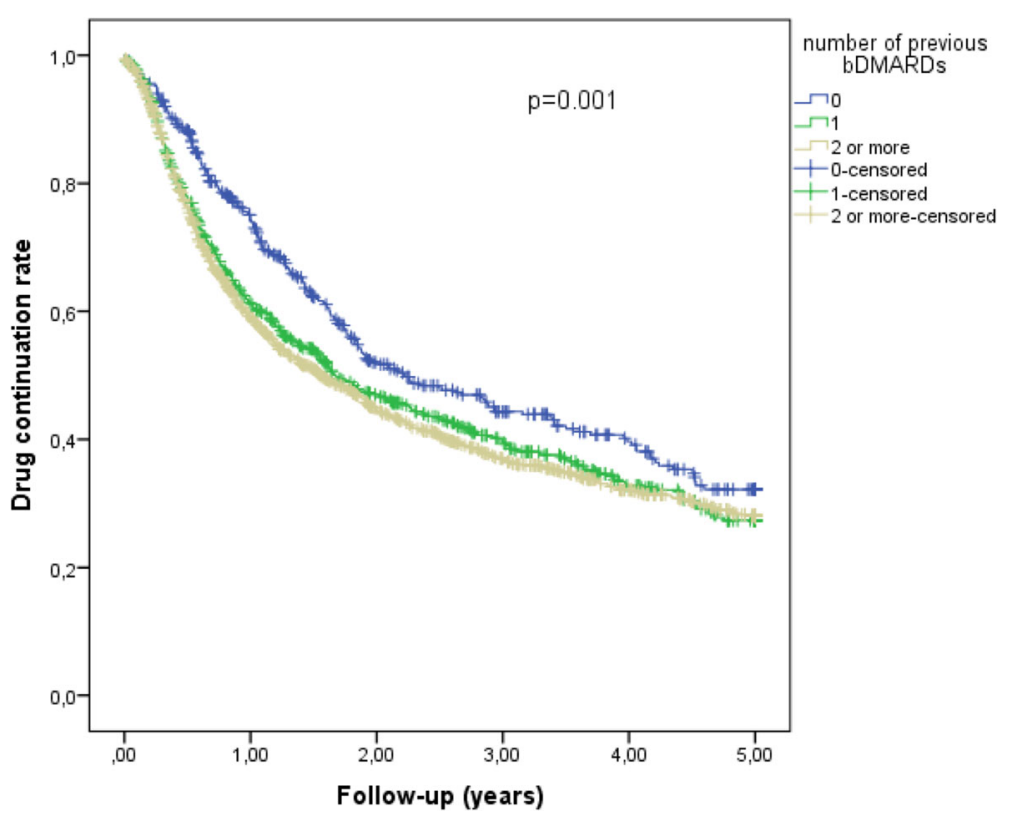

Fig. 1 Survival on abatacept by previous bDMARD exposure. Drug continuation rates in patients treated with no previous bDMARD, 1 previous bDMARD, and $\geq 2$ previous bDMARDs. Significant difference ( $p=0.001$, log-rank test) due to lower abatacept discontinuation in patients with no previous bDMARDs compared to those with 1 or $\geq 2$ previous bDMARDs 
Table 2 Predictors of abatacept discontinuation. Cox regression analysis

\begin{tabular}{|c|c|c|}
\hline & $\begin{array}{l}\text { Unadjusted analysis } \\
\text { HR ( } 95 \% \mathrm{Cl})\end{array}$ & $\begin{array}{l}\text { Multivariate analysis_final model } \\
\text { HR }(95 \% \mathrm{Cl})\end{array}$ \\
\hline \multicolumn{3}{|l|}{ Sex } \\
\hline Male & $0.85(0.75-0.96)$ & $0.86(0.74-0.98)$ \\
\hline \multicolumn{3}{|c|}{ No of previous bDMARDs } \\
\hline$\geq 2$ bDMARDs & Reference (1.0) & * \\
\hline Bionaïve & $0.78(0.68-0.90)$ & * \\
\hline 1 bDMARD & $0.94(0.84-1.05)$ & * \\
\hline \multicolumn{3}{|l|}{ Baseline clinical characteristics } \\
\hline DAS28-CRP (per SD) & $1.11(1.04-1.17)$ & * \\
\hline VAS pain (per SD) & $1.14(1.08-1.21)$ & $1.14(1.07-1.20)$ \\
\hline Current Methotrexate & $0.86(0.78-0.96)$ & $0.85(0.76-0.95)$ \\
\hline HAQ-DI (per SD) & $1.10(1.04-1.17)$ & * \\
\hline Age (per SD) & $0.99(0.94-1.04)$ & * \\
\hline Disease duration (per SD) & $0.98(0.93-1.03)$ & * \\
\hline Current glucocorticoids & $1.08(0.98-1.19)$ & * \\
\hline Current csDMARD & $0.93(0.85-1.03)$ & * \\
\hline i.v. abatacept administration & $1.02(0.92-1.12)$ & * \\
\hline
\end{tabular}

*Not included in the final model. The first multivariate model in the stepwise analysis included sex, bDMARD exposure, DAS28-CRP, VAS pain, methotrexate at baseline, HAQ-DI, glucocorticoids at baseline. Multivariate model includes 1768 patients

variables, male sex (hazard ratio (HR) 0.86; 95\% CI 0.74-0.98), VAS pain (HR 1.14 per standard deviation (SD); 95\% CI 1.07-1.20), and baseline treatment with MTX (HR 0.85; 95\% CI 0.76-0.95) had significant independent effects on abatacept discontinuation (Table 2).

Results were similar in sensitivity analyses including all covariates or all covariates with $p<0.10$ in the univariate models, with and without exclusion of covariates due to collinearity, except that the association between MTX and discontinuation did not reach statistical significance in the model that did not exclude covariates based on multicollinearity (see Additional file 1: Table S1 and S2).

\section{Clinical response}

Twenty-four percent of the patients achieved a EULAR good response at 6 months and $29 \%$ at 12 months (see Additional file 1: Table S3). The corresponding proportions with a EULAR good or moderate response were $59 \%$ and $62 \%$, and with a HAQ response were $31 \%$ and $33 \%$, respectively (see Additional file 1: Table S3 and S4). Among all patients initiating abatacept, $21 \%$ were still on treatment and achieved a EULAR good response at 6 months and at 12 months (LUNDEX-corrected EULAR good response, see Additional file 1: Table S3). LUNDEX-corrected EULAR moderate response was reached by $52 \%$ at 6 months and by $41 \%$ at 12 months (see Additional file 1: Table S3). Twentyseven percent of patients achieved LUNDEX-corrected HAQ response at 6 months, and $23 \%$ did so at 12 months (see Additional file 1: Table S4). Among bionaïve patients, $44 \%$ and $46 \%$ achieved LUNDEX-corrected EULAR good response at 6 and at 12 months, respectively (see Additional file 1: Table S3). These proportions were significantly higher than in those previously treated with 1 or $2 \geq$ bDMARDs (Fig. 2), with similar differences in LUNDEX-corrected HAQ responses (Fig. 3).

There were similar variations for LUNDEX-corrected EULAR moderate response and for proportions attaining LUNDEX-corrected DAS28 remission or low disease activity (see figures in Additional files 2, 3 and 4 and Additional file 1: Tables S3-S5).

\section{Predictors of EULAR response}

Men were more likely than women to achieve a LUNDEXcorrected EULAR good response at 6 months and at 12 months in univariate analysis. These differences also reached statistical significance in the multivariate models (adjusted odds ratio (OR) 2.28, 95\% CI 1.45-3.57 and adjusted OR 2.14, 95\% CI 1.44-3.19) (Table 3). There were also significant associations between being bionaïve at start of abatacept and a LUNDEX-corrected EULAR good response at 6 months and at 12 months, independently of other predictors [adjusted ORs 3.59 (95\% CI 2.25-5.72) at 6 months and 4.29 (95\% CI 2.77-6.65) at 12 months] (Table 3). A higher HAQ score at baseline predicted a lower probability of a LUNDEX-corrected EULAR good response at 6 and at 12 months. This negative association between HAQ-DI and clinical response was also significant in the multivariate analysis (Table 3). Age at abatacept start 


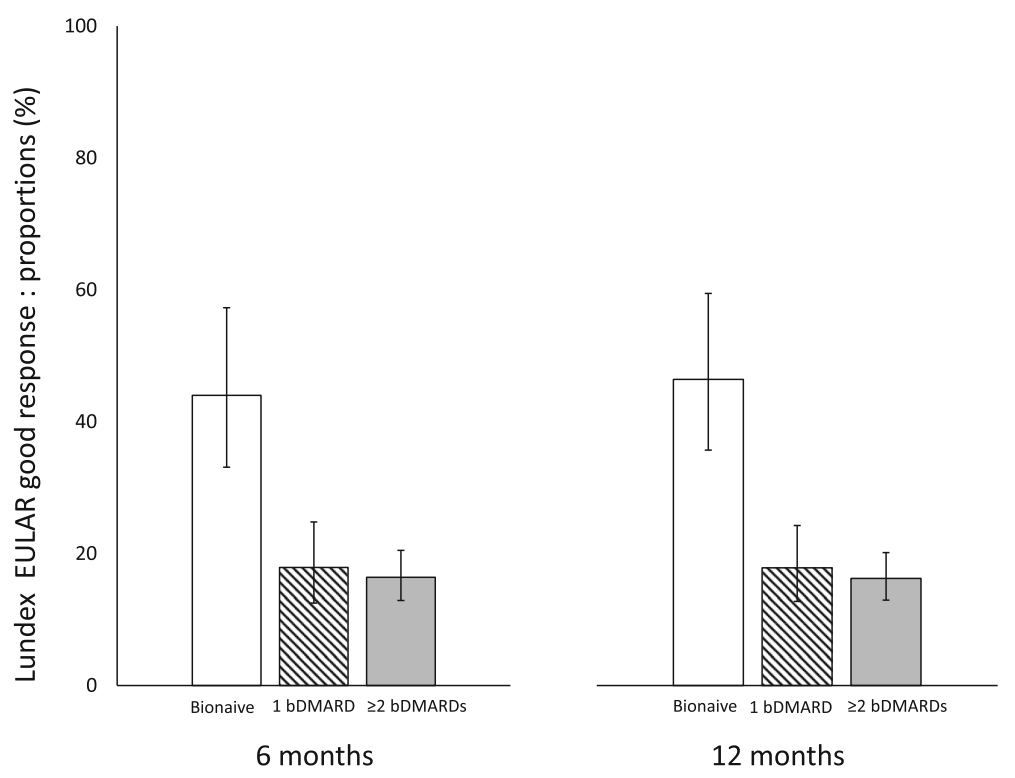

Fig. 2 Proportion of patients achieving LUNDEX-corrected EULAR good response by previous bDMARD exposure. $p<0.001$ for bionaïve patients vs patients treated with 1 and with $\geq 2$ previous bDMARDs. Bars are $95 \% \mathrm{Cl}$

was negatively associated with LUNDEX-corrected EULAR good response at 6 months but not at 12 months. Those on glucocorticoid treatment at baseline were less likely to reach a LUNDEX-corrected EULAR good response at 6 months, but there was no such association at 12 months. Disease duration, abatacept administration route, and treatment with MTX showed some associations with LUNDEXcorrected EULAR good response in the univariate analyses, but not in the multivariate models (Table 3).

Baseline data for those who were included in the multivariate logistic regression analyses for predictors of Lundex-corrected EULAR good response at 6 and 12 months, and those that were excluded due to missing data for outcome or $\geq 1$ of the covariates are listed in Additional file 1: Table S19. Patients with missing data were more likely to receive subcutaneous treatment than intravenous and had slightly lower disease activity, measured by DAS28. Apart from this, there was no major difference between patients with and without missing data for this analysis (see Additional file 1: Table S19).

Biologic DMARD naive patients had higher probability to achieve a LUNDEX-corrected EULAR moderate response at 6 and at 12 months as well. Furthermore, a LUNDEXcorrected EULAR moderate response was predicted in multivariate analysis at 6 months by treatment with a

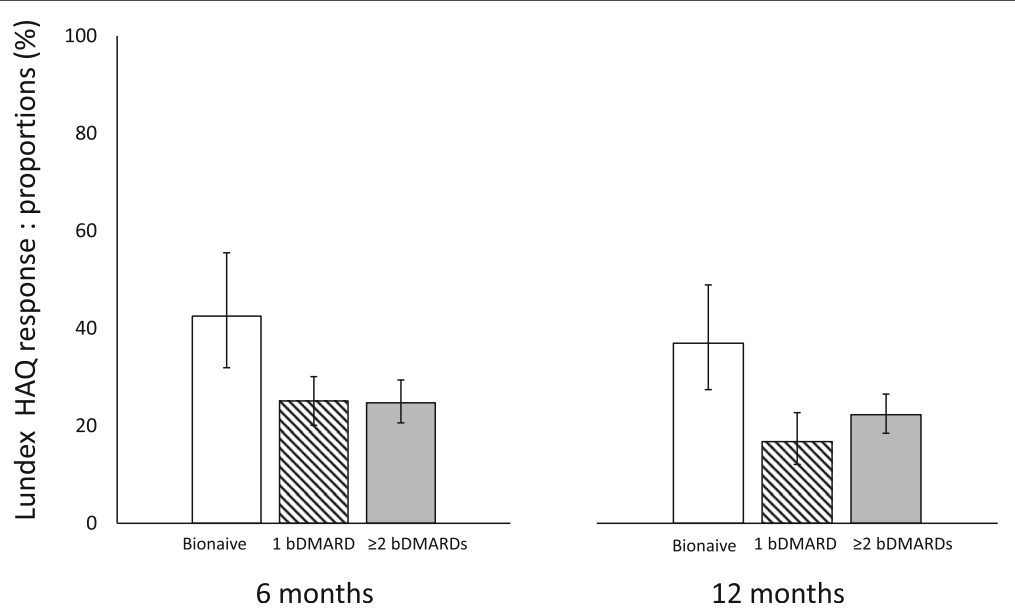

Fig. 3 Proportion of patients achieving LUNDEX-corrected HAQ response by previous bDMARD exposure. $p<0.002$ for bionaïve patients vs patients treated with 1 and with $\geq 2$ previous bDMARDs. Bars are $95 \% \mathrm{Cl}$ 
Table 3 Predictors of LUNDEX-corrected EULAR good response. Odds ratios (95\% confidence intervals)

\begin{tabular}{|c|c|c|c|c|}
\hline & \multicolumn{2}{|l|}{6 months } & \multicolumn{2}{|l|}{12 months } \\
\hline & Univariate & Multivariate & Univariate & Multivariate \\
\hline Male sex & $2.11(1.41-3.13)$ & $2.28(1.45-3.57)$ & $2.46(1.71-3.54)$ & $2.14(1.44-3.19)$ \\
\hline$\geq 2$ bDMARDs & Reference (1.0) & Reference (1.0) & Reference (1.0) & Reference (1.0) \\
\hline Bionaïve & $4.00(2.60-6.15)$ & $3.59(2.25-5.72)$ & $4.45(2.95-6.71)$ & $4.29(2.77-6.65)$ \\
\hline 1 bDMARD & $1.11(0.72-1.72)$ & * & $1.11(0.74-1.69)$ & ** \\
\hline DAS28-CRP (per SD) at baseline & $0.95(0.80-1.14)$ & * & $0.98(0.83-1.16)$ & ** \\
\hline DAS28 (per unit) at baseline & $0.91(0.79-1.04)$ & * & $0.97(0.85-1.10)$ & $* *$ \\
\hline VAS pain (per SD) at baseline & $0.96(0.80-1.15)$ & * & $0.89(0.75-1.06)$ & $* *$ \\
\hline Methotrexate at baseline & $1.36(0.95-1.94)$ & * & $1.46(1.04-2.06)$ & $* *$ \\
\hline HAQ score (per SD) at baseline & $0.64(0.52-0.77)$ & $0.75(0.61-0.93)$ & $0.65(0.54-0.78)$ & $0.74(0.61-0.90)$ \\
\hline Disease duration (per SD) at baseline & $0.79(0.65-0.96)$ & * & $0.72(0.59-0.87)$ & $* *$ \\
\hline Age (per SD) at baseline & $0.76(0.65-0.91)$ & $0.79(0.65-0.96)$ & $0.97(0.82-1.14)$ & $* *$ \\
\hline Glucocorticoids at baseline & $0.59(0.42-0.83)$ & $0.59(0.40-0.86)$ & $0.72(0.52-1.00)$ & $* *$ \\
\hline csDMARD at baseline & $1.40(0.96-2.06)$ & * & $1.25(0.87-1.79)$ & ** \\
\hline s.c. abatacept administration & Reference (1.0) & * & Reference (1.0) & $* *$ \\
\hline i.v. abatacept administration & $0.53(0.38-0.75)$ & * & $0.70(0.51-0.98)$ & ** \\
\hline
\end{tabular}

*Not included in the final model. The first multivariate model in the stepwise analysis included sex, bDMARD exposure, DAS28, methotrexate at baseline, HAQ-DI, disease duration, age, glucocorticoids at baseline, csDMARDs at baseline, and route of abatacept administration. ${ }^{* *}$ Not included in the final model. The first multivariate model in the stepwise analysis included sex, bDMARD exposure, methotrexate at baseline, HAQ-DI, disease duration, glucocorticoids at baseline, and route of abatacept administration. Multivariate model includes 754 patients at 6 months, 829 patients at 12 months

csDMARD at baseline, and at 12 months by male sex (see Additional file 1: Table S6). Results of the sensitivity analyses on predictors of LUNDEX-corrected responses were largely similar to those of the main analyses (see Additional file 1: Tables S7-S18).

\section{Predictors of $\mathrm{HAQ}$ response}

Bionaïve patients were more likely than those with $\geq 2$ previous bDMARDs to achieve a LUNDEX-corrected HAQ response at 6 and 12 months, independently of other predictors [adjusted OR 2.31 (95\% CI 1.49-3.60) and 2.05 (95\% CI 1.37-3.07)] (Table 4). HAQ score at baseline showed independent predictive value for LUNDEXcorrected HAQ response at 6 months (adjusted OR 1.73 per SD; 95\% CI 1.46-2.05) but not at 12 months (Table 4). Disease duration had a negative association with LUNDEXcorrected HAQ response in the adjusted model at 6 months (adjusted OR 0.74; 95\% CI 0.61-0.89) but not at 12 months (Table 4). DAS28, DAS28-CRP, VAS pain, and treatment with MTX at baseline were positively associated with LUNDEX-corrected HAQ response at 6 and 12 months in univariate analyses. However, no predictive value of DAS28, DAS28-CRP, VAS pain, and treatment with MTX was found when adjusting for confounding variables (Table 4).

\section{Discussion}

In this study of a large, national cohort, we found that bionaïve patients had a longer survival on abatacept as compared to bDMARD experienced patients. However, multivariate analyses demonstrated that this was to some extent explained by other factors. Female sex and severe pain at treatment start were independently associated with reduced survival on abatacept treatment, and patients on methotrexate were less likely to discontinue abatacept. On the other hand, bionaïve patients had significantly higher likelihood of achieving a clinical and functional response on treatment as compared to bDMARD experienced patients. Lack of previous bDMARD exposure, male sex, and a low HAQ score at treatment start were independent predictors of a good clinical response to abatacept both at 6 and at 12 months. Lack of previous bDMARD exposure was also the only predictor of a good functional response both at 6 and at 12 months.

In observational studies, survival on drug is considered a good indirect and composite measure of effectiveness, safety, and tolerability of a given treatment [23]. While a significant amount of data regarding survival on drug exists for TNF inhibitors, the lack of studies on abatacept has been recognized [24]. In a previous study from the SRQ, drug survival on TNF inhibitors was similar to the present study [25]. By contrast, survival on drug for patients treated with abatacept as their second bDMARD was slightly higher than the overall drug continuation rate in this study (64\% compared to $55 \%$ at 1 year) [25]. This could be partly due to the different time periods during which the patients were recruited. Frisell et al. included patients starting bDMARDs between 2010 and 2016 whereas our inclusion period was 2006-2017. 
Table 4 Predictors of LUNDEX-corrected HAQ response. Odds ratios (95\% confidence intervals)

\begin{tabular}{|c|c|c|c|c|}
\hline & \multicolumn{2}{|l|}{6 months } & \multicolumn{2}{|l|}{12 months } \\
\hline & Univariate & Multivariate & Univariate & Multivariate \\
\hline Male sex & $1.07(0.73-1.58)$ & * & $1.32(0.91-1.90)$ & ** \\
\hline$\geq 2$ bDMARDs & Reference (1.0) & Reference (1.0) & Reference (1.0) & Reference (1.0) \\
\hline Bionaïve & $2.25(1.50-3.38)$ & $2.31(1.49-3.60)$ & $2.05(1.37-3.07)$ & $2.05(1.37-3.07)$ \\
\hline 1 bDMARD & $1.02(0.71-1.47)$ & * & $0.70(0.48-1.04)$ & $* *$ \\
\hline DAS28-CRP (per SD) at baseline & $1.48(1.26-1.74)$ & * & $1.38(1.17-1.62)$ & $* *$ \\
\hline DAS28 (per unit) at baseline & $1.40(1.23-1.60)$ & * & $1.27(1.12-1.45)$ & $* *$ \\
\hline VAS pain (per SD) at baseline & $1.45(1.23-1.70)$ & * & $1.24(1.05-1.47)$ & $* *$ \\
\hline Methotrexate at baseline & $1.50(1.10-2.05)$ & * & $1.39(1.01-1.90)$ & $* *$ \\
\hline HAQ score (per SD) at baseline & $1.52(1.29-1.78)$ & $1.73(1.46-2.05)$ & $1.24(1.06-1.45)$ & $* *$ \\
\hline Disease duration (per SD) at baseline & $0.77(0.65-0.91)$ & $0.74(0.61-0.89)$ & $0.78(0.65-0.92)$ & $* *$ \\
\hline Age (per SD) at baseline & $0.93(0.80-1.08)$ & * & $1.00(0.86-1.17)$ & ** \\
\hline Glucocorticoids at baseline & $0.75(0.55-1.01)$ & * & $0.83(0.61-1.13)$ & $* *$ \\
\hline csDMARDs at baseline & $1.30(0.94-1.81)$ & * & $1.17(0.84-1.62)$ & $* *$ \\
\hline s.c. abatacept administration & Reference (1.0) & * & Reference (1.0) & * \\
\hline i.v. abatacept administration & $0.98(0.73-1.33)$ & * & $0.97(0.71-1.32)$ & $* *$ \\
\hline
\end{tabular}

*Not included in the final model. The first multivariate model in the stepwise analysis included bDMARD exposure, DAS28-CRP, DAS28, VAS pain, methotrexate at baseline, HAQ-DI, disease duration, glucocorticoids at baseline, and csDMARDs at baseline. **Not included in the final model. The first multivariate model in the stepwise analysis included sex, bDMARD exposure, DAS28-CRP, DAS28, VAS pain, methotrexate at baseline, HAQ-DI, and disease duration. Multivariate model includes 862 patients at 6 months and 943 at 12 months

During the first period after abatacept was licensed for RA treatment in Europe, this drug was mainly used in patients with refractory disease, after failure to different previous bDMARDs and thus with a higher risk of ensuing failure to abatacept too. A further study using data from the SRQ to analyze survival on drug and predictors for discontinuation of tocilizumab in RA patients also reported a drug retention rate of $64 \%$ after 1 year [26]. The sample size of that study was smaller (530 patients) in comparison with the present study, and patients with no follow-up data at 1 year were excluded, thus partially accounting for the above differences in outcome.

Studies on data from other registers, focusing on treatment with bDMARDs other than abatacept reported better response and survival on drug in bionaïve patients as compared with bDMARD experienced patients [27-31]. Several studies described the same pattern for abatacepttreated patients [32-34], which is in line with our finding, although we suggest that this may partly be due to confounding by other factors.

With respect to clinical response, there may be a more direct role of previous bDMARD exposure. Better clinical response to abatacept in bionaïve than in bDMARD experienced patients was in accordance with clinical trial findings $[22,35,36]$ and with the results from other observational studies [34, 37]. To our knowledge, only one study analyzed the long-term effect of abatacept on function in real life, and, in contrast to our study, the results did not show any difference across bDMARD exposures. However, a greater improvement in HAQ-DI was observed in the bionaïve group after adjusting for age and baseline HAQ-DI [32]. The discrepancy could be explained by different cut-offs for the definition of HAQ response-improvement of $\geq 0.3$, in accordance with previous clinical trials [22], in the present study, as opposed to the minimal important difference in HAQDI in RA $(\geq 0.22)[38,39]$ in the other study.

Differences in pain perception could account at least for a part of the observed discrepancy in outcomes between women and men. Several studies found male sex to be a predictor of better treatment response or remission in early RA [40-45]. Results from the Danish DANBIO register showed a predictive value of male sex for treatment response to TNF inhibitors, even though the finding was limited to the cohort of early RA, whereas no difference between male and female patients was observed in established RA [46]. However, in the DANBIO study, the response was categorized as no response vs. EULAR moderate or good response and that could account for the discrepancy with our results. Indeed, our study demonstrated that the strong predictive value of sex for EULAR good response differed from the weaker association with the less stringent EULAR moderate or good response. Data on TNF inhibitors from the British register showed no sexrelated differences in EULAR response, but they did show lower DAS28 remission rate for female as compared with male patients [47]. Interestingly, the only observational study that focused on the predictive value of sex in 
patients treated with abatacept [48] and a study on abatacept and tocilizumab from the Danish register [49] did not show any associations between female sex and treatment response. Again, the less stringent EULAR moderate or good response was used as outcome in these studies. The inconsistencies between the different studies show that the relation between sex and treatment response in RA is far from clear. Of note, sex did not predict HAQ response in the present study.

Our data on the benefit of methotrexate are in line with those from an Australian retrospective cohort [33] and the ACTION study, where association of methotrexate with a longer survival on abatacept was also demonstrated in patients previously exposed to bDMARDs [34]. The predictive value of pain for survival on abatacept was reported in the ACTION study too, with results going in the same direction as in our study [34].

The negative correlation between HAQ-DI at baseline and clinical response was in accordance with data on TNF inhibitors from the British Register [47] and with abatacept data from the Japanese register [50].

Limitations of the present study are related to the observational design and to the large number of patients with missing data, which could impact the value of our results. However, such observational design is considered to be the most appropriate to study the long-term survival on drug and the long-term effect of a drug. We could not take into account anti-citrullinated protein antibody and rheumatoid factor status of our patients, since data on such tests are not included in the register. Furthermore, data on comorbidities, which might influence drug survival and treatment response, were not available. We did not stratify analyses of drug survival by reason for abatacept discontinuation, as data on this in the SRQ have not been validated.

Strengths of this study include the large sample size and the long follow-up. This is one of the largest cohorts worldwide of RA patients treated with abatacept, second only to the Canadian Orencia Response Program (ORP) cohort [32]. The use of LUNDEX correction for the efficacy outcomes allowed to investigate the effect of abatacept combined with tolerability, which is an outcome that is relevant to the patients. As the present study was based on a national quality register with high coverage, the study subjects are representative for patients starting abatacept for RA in Sweden. On the other hand, the results may not apply to patient groups with a different ethnic background, or to study settings with distinct availability of abatacept and other bDMARDs, regulatory guidelines, etc.

\section{Conclusion}

The analysis of one of the largest cohorts of abatacepttreated RA patients gave insights on the differences between bionaïve and bDMARD experienced patients in term of treatment persistency as well as in terms of clinical and functional response. We demonstrated that bionaïve patients had longer survival on abatacept as well as better clinical and functional response to this drug as compared to bDMARD experienced patients. Sex, and to some extent baseline disease severity, also influenced outcome of treatment with abatacept. Insights on the efficacy and tolerability of abatacept based on such data from a real-life setting may be useful for clinical practice.

\section{Supplementary information}

Supplementary information accompanies this paper at https://doi.org/10. 1186/s13075-020-2100-y.

Additional file 1. Additional tables. Tables with additional data and analysis.

Additional file 2 Proportions of patients achieving LUNDEX corrected EULAR moderate response by previous bDMARD exposure. ${ }^{*} p<0.001$ for bionaïve patients vs patients treated with 1 and with $\geq 2$ previous bDMARDs. Bars are $95 \% \mathrm{Cl}$.

Additional file 3. Proportions of patients achieving LUNDEX corrected DAS 28 remission by previous bDMARD exposure. ${ }^{*} p<0.001$ for bionaïve patients vs patients treated with 1 and with $\geq 2$ previous bDMARDs. Bars are $95 \% \mathrm{Cl}$.

Additional file 4. Proportions of patients achieving LUNDEX corrected DAS 28 low disease activity by previous bDMARD exposure. ${ }^{*} p<0.001$ for bionaïve patients vs patients treated with 1 and with $\geq 2$ previous bDMARDs. Bars are $95 \% \mathrm{Cl}$.

\begin{abstract}
Abbreviations
bDMARDs: Biologic disease-modifying antirheumatic drugs; $\mathrm{Cl}$ : Confidence interval; csDMARD: Conventional synthetic disease-modifying antirheumatic drugs; DAS28: Disease activity score on 28 joints; DMARDs: Diseasemodifying antirheumatic drugs; HAQ: Health Assessment Questionnaire; HAQ-DI: Health Assessment Questionnaire Disability Index; HR: Hazard ratio; MTX: Methotrexate; OR: Odds ratio; RA: Rheumatoid arthritis; SRQ: Swedish Rheumatology Quality Register; TNF: Tumor necrosis factor; VAS: Visual analog scale
\end{abstract}

\section{Acknowledgements}

Not applicable.

\section{Authors' contributions}

GC performed the statistical analysis, participated in the interpretation of the results, and wrote the first draft of the manuscript. MW contributed in data managing and analyses of the data. JÅN participated in the interpretation of the results. MC participated in the interpretation of the results. LTHJ participated in the interpretation of the results. SS participated in the study design and the interpretation of the results. CT participated in the study design, wrote the study protocol, participated in the interpretation of the results, and helped draft the manuscript. All authors were involved in revising the manuscript critically. All authors read and approved the final manuscript.

\section{Funding}

This work was supported by the Swedish Research Council [2015-02228], Lund University [ALFSKANE-446501], and an unrestricted grant from BristolMyers Squibb. Open access funding provided by Lund University. corresponding author on reasonable request. 


\section{Ethics approval and consent to participate}

The study was approved by the Regional Ethics Committee in Stockholm, Sweden, and it was conducted in accordance with the Declaration of Helsinki.

\section{Consent for publication}

Not applicable.

\section{Competing interests}

Cagnotto G. has received consulting fee from Novartis and has no disclosures related to this paper.

Compagno M. has received speaking fee from Abbvie and has no disclosures related to this paper.

Willim M. and Nilsson JÅ. have no disclosures.

Jacobsson L.T.H. has received lecture and consulting fees from Pfizer, Abbvie, Novartis, Eli-Lily, and Janssen.

Saevarsdottir S. is a part-time employee of deCODE Genetics, working on research unrelated to this subject.

Turesson C. has received consulting fees from Roche, speaking fees from Abbvie, Bristol Myers-Squibb, Pfizer, Roche, and an unrestricted grant for this study from Bristol Myers-Squibb.

\section{Author details}

${ }^{1}$ Rheumatology, Department of Clinical Sciences, Lund University, Malmö, Sweden. Department of Rheumatology, Skåne University Hospital, Lund, Sweden. ${ }^{3}$ Rheumatology, Department of Clinical Sciences, Lund University, Lund, Sweden. ${ }^{4}$ Department of Rheumatology \& Inflammation Research, The Sahlgrenska Academy, University of Gothenburg, Gothenburg, Sweden. ${ }^{5}$ Unit of Translational Epidemiology, Institute of Environmental Medicine, Karolinska Institutet, Stockholm, Sweden. ${ }^{6}$ Rheumatology Unit, Department of Medicine, Karolinska Institutet, Solna, Stockholm, Sweden. ${ }^{7}$ Department of

Rheumatology, Skåne University Hospital, Malmö, Sweden.

Received: 2 October 2019 Accepted: 9 January 2020

Published online: 22 January 2020

\section{References}

1. Lipsky PE, van der Heijde DM, St Clair EW, Furst DE, Breedveld FC, Kalden JR, et al. Infliximab and methotrexate in the treatment of rheumatoid arthritis. Anti-tumor necrosis factor trial in rheumatoid arthritis with concomitant therapy study group. N Engl J Med. 2000;343(22):1594-602.

2. Klareskog L, van der Heijde D, de Jager JP, Gough A, Kalden J, Malaise M, et al. Therapeutic effect of the combination of etanercept and methotrexate compared with each treatment alone in patients with rheumatoid arthritis: double-blind randomised controlled trial. Lancet. 2004;363(9410):675-81.

3. Weinblatt ME, Kremer JM, Bankhurst AD, Bulpitt KJ, Fleischmann RM, Fox RI, et al. A trial of etanercept, a recombinant tumor necrosis factor receptor: FC fusion protein, in patients with rheumatoid arthritis receiving methotrexate. N Engl J Med. 1999;340(4):253-9.

4. Breedveld FC, Weisman MH, Kavanaugh AF, Cohen SB, Pavelka K, van Vollenhoven $\mathrm{R}$, et al. The PREMIER study: a multicenter, randomized, doubleblind clinical trial of combination therapy with adalimumab plus methotrexate versus methotrexate alone or adalimumab alone in patients with early, aggressive rheumatoid arthritis who had not had previous methotrexate treatment. Arthritis Rheum. 2006;54(1):26-37.

5. Dixon WG, Carmona L, Finckh A, Hetland ML, Kvien TK, Landewe R, et al. EULAR points to consider when establishing, analysing and reporting safety data of biologics registers in rheumatology. Ann Rheum Dis. 2010;69(9):1596-602.

6. Wolfe F, Michaud K. The Hawthorne effect, sponsored trials, and the overestimation of treatment effectiveness. J Rheumatol. 2010;37(11): 2216-20.

7. Smolen JS, Aletaha D, Bijlsma JW, Breedveld FC, Boumpas D, Burmester G, et al. Treating rheumatoid arthritis to target: recommendations of an international task force. Ann Rheum Dis. 2010;69(4):631-7.

8. Smolen JS, Landewe R, Breedveld FC, Buch M, Burmester G, Dougados M, et al. EULAR recommendations for the management of rheumatoid arthritis with synthetic and biological disease-modifying antirheumatic drugs: 2013 update. Ann Rheum Dis. 2014;73(3):492-509.
9. Chatzidionysiou K, Askling J, Eriksson J, Kristensen LE, van Vollenhoven R. Effectiveness of TNF inhibitor switch in RA: results from the national Swedish register. Ann Rheum Dis. 2015;74(5):890-6.

10. Chatzidionysiou K, Lie E, Nasonov E, Lukina G, Hetland ML, Tarp U, et al. Effectiveness of disease-modifying antirheumatic drug co-therapy with methotrexate and leflunomide in rituximab-treated rheumatoid arthritis patients: results of a 1-year follow-up study from the CERERRA collaboration. Ann Rheum Dis. 2012;71(3):374-7.

11. lannone F, Courvoisier DS, Gottenberg JE, Hernandez MV, Lie E, Canhao H, et al. Body mass does not impact the clinical response to intravenous abatacept in patients with rheumatoid arthritis. Analysis from the "panEuropean registry collaboration for abatacept (PANABA). Clin Rheumatol 2017;36(4):773-779.

12. Finckh A, Neto D, lannone F, Loza E, Lie E, van Riel P, et al. The impact of patient heterogeneity and socioeconomic factors on abatacept retention in rheumatoid arthritis across nine European countries. RMD open. 2015;1(1): e000040.

13. Nusslein HG, Alten R, Galeazzi M, Lorenz HM, Boumpas D, Nurmohamed MT, et al. Real-world effectiveness of abatacept for rheumatoid arthritis treatment in European and Canadian populations: a 6-month interim analysis of the 2-year, observational, prospective ACTION study. BMC Musculoskelet Disord. 2014;15:14.

14. Eriksson JK, Askling J, Arkema EV. The Swedish Rheumatology Quality Register: optimisation of rheumatic disease assessments using registerenriched data. Clin Exp Rheumatol. 2014:32(5 Suppl 85):S-147-9.

15. Kristensen LE, Saxne T, Geborek P. The LUNDEX, a new index of drug efficacy in clinical practice: results of a five-year observational study of treatment with infliximab and etanercept among rheumatoid arthritis patients in southern Sweden. Arthritis Rheum. 2006;54(2):600-6.

16. Gottenberg JE, Courvoisier DS, Hernandez MV, lannone F, Lie E, Canhao H, et al. Brief report: association of rheumatoid factor and anti-citrullinated protein antibody positivity with better effectiveness of abatacept: results from the Pan-European Registry Analysis. Arthritis \& rheumatology (Hoboken). 2016;68(6):1346-52.

17. Courvoisier DS, Alpizar-Rodriguez D, Gottenberg JE, Hernandez MV, lannone

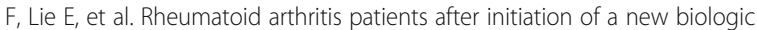
agent: trajectories of disease activity in a large multinational cohort study. EBioMedicine. 2016:11:302-6.

18. Neovius M, Simard J, Sundstrom A, Jacobsson L, Geborek P, Saxne T, et al. Generalisability of clinical registers used for drug safety and comparative effectiveness research: coverage of the Swedish Biologics Register. Ann Rheum Dis. 2011;70(3):516-9.

19. van Gestel $A M$, Prevoo ML, van't Hof MA, van Rijswijk MH, van de Putte LB, van Riel PL. Development and validation of the European League Against Rheumatism response criteria for rheumatoid arthritis. Comparison with the preliminary American College of Rheumatology and the World Health Organization/International League Against Rheumatism Criteria. Arthritis Rheum. 1996;39(1):34-40.

20. van Gestel AM, Haagsma CJ, van Riel PL. Validation of rheumatoid arthritis improvement criteria that include simplified joint counts. Arthritis Rheum. 1998:41(10):1845-50.

21. Fries JF, Spitz P, Kraines RG, Holman HR. Measurement of patient outcome in arthritis. Arthritis Rheum. 1980;23(2):137-45.

22. Genovese MC, Becker JC, Schiff M, Luggen M, Sherrer Y, Kremer J, et al. Abatacept for rheumatoid arthritis refractory to tumor necrosis factor alpha inhibition. N Engl J Med. 2005;353(11):1114-23..

23. Silvagni E, Bortoluzzi A, Carrara G, Zanetti A, Govoni M, Scire CA. Comparative effectiveness of first-line biological monotherapy use in rheumatoid arthritis: a retrospective analysis of the RECord-linkage on rheumatic diseases study on health care administrative databases. BMJ Open. 2018;8(9):e021447.

24. Souto A, Maneiro JR, Gomez-Reino JJ. Rate of discontinuation and drug survival of biologic therapies in rheumatoid arthritis: a systematic review and meta-analysis of drug registries and health care databases. Rheumatology (Oxford). 2016:55(3):523-34.

25. Frisell T, Dehlin M, Di Giuseppe D, Feltelius N, Turesson C, Askling J. Comparative effectiveness of abatacept, rituximab, tocilizumab and TNFi biologics in RA: results from the nationwide Swedish register. Rheumatology (Oxford). 2019;58(8):1367-77.

26. Forsblad-d'Elia H, Bengtsson K, Kristensen LE, Jacobsson LT. Drug adherence, response and predictors thereof for tocilizumab in patients with rheumatoid 
arthritis: results from the Swedish biologics register. Rheumatology (Oxford). 2015:54(7):1186-93.

27. Du Pan SM, Scherer A, Gabay C, Finckh A. Differential drug retention between anti-TNF agents and alternative biological agents after inadequate response to an anti-TNF agent in rheumatoid arthritis patients. Ann Rheum Dis. 2012;71(6):997-9.

28. Gomez-Reino JJ, Maneiro JR, Ruiz J, Rosello R, Sanmarti R, Romero AB. Comparative effectiveness of switching to alternative tumour necrosis factor (TNF) antagonists versus switching to rituximab in patients with rheumatoid arthritis who failed previous TNF antagonists: the MIRAR study. Ann Rheum Dis. 2012;71(11):1861-4.

29. Gomez-Reino JJ, Rodriguez-Lozano C, Campos-Fernandez C, Montoro M, Descalzo MA, Carmona L. Change in the discontinuation pattern of tumour necrosis factor antagonists in rheumatoid arthritis over 10 years: data from the Spanish registry BIOBADASER 2.0. Ann Rheum Dis. 2012;71(3):382-5.

30. Greenberg JD, Reed G, Decktor D, Harrold L, Furst D, Gibofsky A, et al. A comparative effectiveness study of adalimumab, etanercept and infliximab in biologically naive and switched rheumatoid arthritis patients: results from the US CORRONA registry. Ann Rheum Dis. 2012;71(7):1134-42.

31. Remy A, Avouac J, Gossec L, Combe B. Clinical relevance of switching to a second tumour necrosis factor-alpha inhibitor after discontinuation of a first tumour necrosis factor-alpha inhibitor in rheumatoid arthritis: a systematic literature review and meta-analysis. Clin Exp Rheumatol. 2011;29(1):96-103.

32. Pope JE, Rampakakis E, Sampalis J. The durability of abatacept as a first and subsequent biologic and improvement in $\mathrm{HAQ}$ from a large multi-site realworld study. Semin Arthritis Rheum. 2015;44(5):499-505.

33. Jones $G$, Hall $S$, Bird P, Littlejohn G, Tymms K, Youssef P, et al. A retrospective review of the persistence on bDMARDs prescribed for the treatment of rheumatoid arthritis in the Australian population. Int J Rheum Dis. 2018;21(8):1581-90.

34. Alten R, Mariette X, Lorenz HM, Galeazzi M, Cantagrel A, Nusslein HG, et al. Real-world predictors of 12-month intravenous abatacept retention in patients with rheumatoid arthritis in the ACTION observational study. RMD open. 2017;3(2):e000538.

35. Kremer JM, Genant HK, Moreland LW, Russell AS, Emery P, AbudMendoza $C$, et al. Effects of abatacept in patients with methotrexateresistant active rheumatoid arthritis: a randomized trial. Ann Intern Med. 2006;144(12):865-76.

36. Schiff M, Keiserman M, Codding C, Songcharoen S, Berman A, Nayiager S, et al. Efficacy and safety of abatacept or infliximab vs placebo in ATTEST: a phase III, multi-centre, randomised, double-blind, placebo-controlled study in patients with rheumatoid arthritis and an inadequate response to methotrexate. Ann Rheum Dis. 2008;67(8):1096-103.

37. Takahashi N, Kojima T, Kaneko A, Kida D, Hirano Y, Fujibayashi T, et al. Longterm efficacy and safety of abatacept in patients with rheumatoid arthritis treated in routine clinical practice: effect of concomitant methotrexate after 24 weeks. J Rheumatol. 2015;42(5):786-93.

38. Wells GA, Tugwell P, Kraag GR, Baker PR, Groh J, Redelmeier DA. Minimum important difference between patients with rheumatoid arthritis: the patient's perspective. J Rheumatol. 1993;20(3):557-60.

39. Kosinski M, Zhao SZ, Dedhiya S, Osterhaus JT, Ware JE Jr. Determining minimally important changes in generic and disease-specific health-related quality of life questionnaires in clinical trials of rheumatoid arthritis. Arthritis Rheum. 2000;43(7):1478-87.

40. Forslind K, Hafstrom I, Ahlmen M, Svensson B. Sex: a major predictor of remission in early rheumatoid arthritis? Ann Rheum Dis. 2007;66(1):46-52.

41. Makinen $\mathrm{H}$, Hannonen $\mathrm{P}$, Sokka T. Sex: a major predictor of remission as measured by 28-joint Disease Activity Score (DAS28) in early rheumatoid arthritis? Ann Rheum Dis. 2008;67(7):1052-3.

42. Kvien TK, Uhlig T, Odegard S, Heiberg MS. Epidemiological aspects of rheumatoid arthritis: the sex ratio. Ann N Y Acad Sci. 2006; 1069:212-22.

43. Mancarella L, Bobbio-Pallavicini F, Ceccarelli F, Falappone PC, Ferrante A, Malesci D, et al. Good clinical response, remission, and predictors of remission in rheumatoid arthritis patients treated with tumor necrosis factor-alpha blockers: the GISEA study. J Rheumatol. 2007;34(8):1670-3.

44. Burmester GR, Ferraccioli G, Flipo RM, Monteagudo-Saez I, Unnebrink K, Kary $S$, et al. Clinical remission and/or minimal disease activity in patients receiving adalimumab treatment in a multinational, open-label, twelve-week study. Arthritis Rheum. 2008:59(1):32-41.

45. van der Heijde D, Klareskog L, Landewe R, Bruyn GA, Cantagrel A, Durez P, et al. Disease remission and sustained halting of radiographic progression with combination etanercept and methotrexate in patients with rheumatoid arthritis. Arthritis Rheum. 2007;56(12):3928-39.

46. Jawaheer D, Olsen J, Hetland ML. Sex differences in response to anti-tumor necrosis factor therapy in early and established rheumatoid arthritis -results from the DANBIO registry. J Rheumatol. 2012;39(1):46-53.

47. Hyrich KL, Watson KD, Silman AJ, Symmons DP. Predictors of response to anti-TNF-alpha therapy among patients with rheumatoid arthritis: results from the British Society for Rheumatology Biologics Register. Rheumatology (Oxford). 2006;45(12):1558-65.

48. Nourisson C, Soubrier M, Mulliez A, Baillet A, Bardin T, Cantagrel A, et al. Impact of gender on the response and tolerance to abatacept in patients with rheumatoid arthritis: results from the 'ORA' registry. RMD open. 2017; 3(2):e000515.

49. Leffers HC, Ostergaard M, Glintborg B, Krogh NS, Foged H, Tarp U, et al. Efficacy of abatacept and tocilizumab in patients with rheumatoid arthritis treated in clinical practice: results from the nationwide Danish DANBIO registry. Ann Rheum Dis. 2011;70(7):1216-22.

50. Kojima T, Takahashi N, Kaneko A, Kida D, Hirano Y, Fujibayashi T, et al. Predictive factors for achieving low disease activity at 52 weeks after switching from tumor necrosis factor inhibitors to abatacept: results from a multicenter observational cohort study of Japanese patients. Clin Rheumatol. 2016:35(1):219-25.

\section{Publisher's Note}

Springer Nature remains neutral with regard to jurisdictional claims in published maps and institutional affiliations.
Ready to submit your research? Choose BMC and benefit from:

- fast, convenient online submission

- thorough peer review by experienced researchers in your field

- rapid publication on acceptance

- support for research data, including large and complex data types

- gold Open Access which fosters wider collaboration and increased citations

- maximum visibility for your research: over $100 \mathrm{M}$ website views per year

At BMC, research is always in progress.

Learn more biomedcentral.com/submissions 